\title{
Measurement of motor conduction velocity with Hopf's technique in the diagnosis of mild peripheral neuropathies
}

\author{
B R OSSI, F S A R U C CI, A N D A T E F A N I N I \\ From the Second Clinic of Neurology of the University of Pisa, Italy
}

SUMMARY Hopf's technique was used to measure motor nerve conduction velocity of fibres in the deep peroneal nerve in clinical conditions where damage to the peripheral nervous system was probable. A particular distribution of motor nerve fibre conduction velocity was shown by the analysis of the findings in some of the groups investigated, illustrating the advantages of this method as compared with routine neurophysiological tests.

In measuring motor nerve conduction velocity (MNCV) the value of only the fastest fibres usually is considered. MNCV measurement of all fibres can give a better impression of nerve function. Such measurement is possible with Hopf's tcchnique, ${ }^{12}$ which among the methods proposed for this purpose, is the most reliable. ${ }^{3}$ We used this method to study the MNCV in some clinical conditions where damage to the peripheral nervous system was probable (subjects exposed to exogenous toxic agents and those with diabetes and uraemia) to evaluate the possible advantages of this technique as compared with routine neurophysiological tests in mild peripheral neuropathies.

\section{Patients and methods}

We examined 13 diabetic subjects (illness duration from 3 to 20 years), 13 chronic uraemic subjects (eight on dialysis, five on conservative therapy, diet), 20 subjects exposed to leather glues (workers from three separate shoe factories with different risk factors).

The data of these groups have been compared with those obtained in a control group of 21 normal volunteers. The following tests were performed: measurement of the MNCV of the deep peroneal nerve with the usual technique, and on the same nerve by Hopf's technique. The nerve was stimulated at the head of the fibula and at the ankle with paired rectangular supramaximal $0.2 \mathrm{~ms}$ stimuli, recordings percutane-

Address for reprint requests: Dr Bruno Rossi, Clinica Neurologica $2^{\circ}$, Universita di Pisa, Spedali Riuniti, S Chiara, Via Roma, Pisa, Italy. Accepted 1 April 1980 ously from the extensor digitorum brevis muscle. The intershock interval was varied, by either 0.1 or $0.2 \mathrm{~ms}$ at a time, starting from the minimum delay at which the smallest potential was elicited by proximal stimulation. At each time interval we recorded the increment in amplitude of the potential, until the delay between the two stimuli was such that there was no further increase.

Analysis of the change in amplitude of the muscle potential for each time interval between the proximal and distal stimulus was made, a particular velocity value corresponding to each time interval. Average histograms of range of conduction velocity against amplitude of the potential were constructed for each particular group of patients, taking as reference point the median value of motor conduction velocity for each subject. Calculating average amplitude of the median value in the group, the same measurement was then performed, metre by metre, for all conduction values and their respective amplitudes to the left and right of the median value. In the MNCV measurement we deliberately did not consider the absolute refractory period, which increases in pathological conditions, ${ }^{4}$ the proximal stimulus, although finding the nerve immediately below the electrode in the refractory period, probably succeeds in exciting the nerve at a more distal point due to current volume conduction.

\section{Results}

The figure and the table show that there was no difference in conduction velocity between younger and older normal subjects. The wide range of velocities in the younger normal subjects was due 

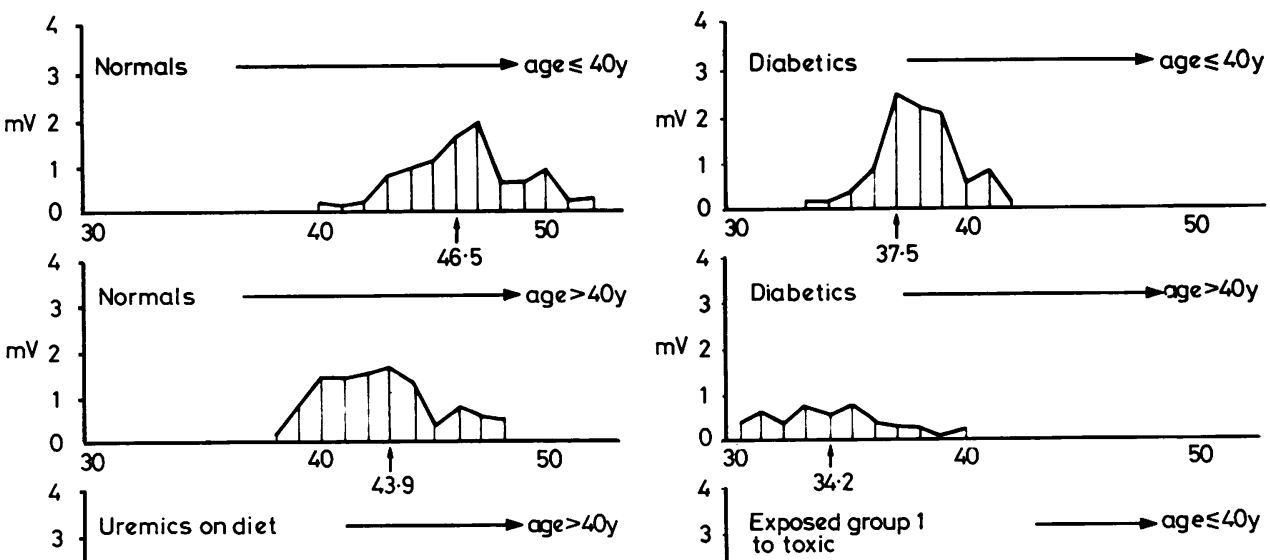

$\mathrm{mV} 2$

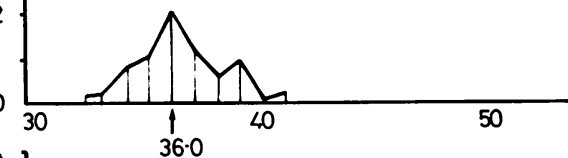

$\mathrm{mV} 2$

Exposed group
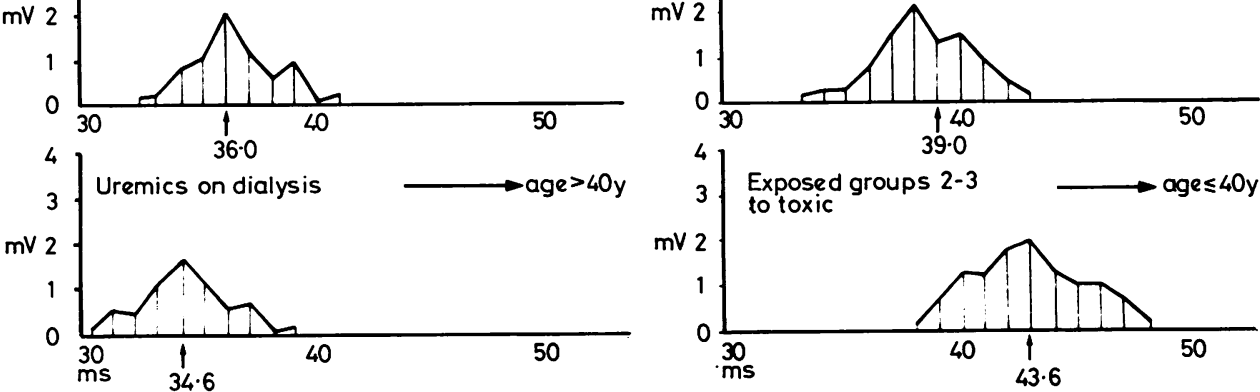

Figure Histograms of individual groups of patients or control subjects. Abscissa, values of conduction velocity $(\mathrm{m} / \mathrm{s}), \mathrm{MNCV}$ value indicated by the arrow represents the average median values of all subjects in that group. Ordinate, average amplitude variations $(m v)$ of the potentials by proximal stimulation, obtained at different time intervals betwen proximal and distal stimulus.

Table Maximum, minimum and range of velocities (Means \pm 1 SD are shown)

\begin{tabular}{|c|c|c|c|c|c|c|c|}
\hline Group & $\begin{array}{l}\text { Age } \\
(y r)\end{array}$ & $\begin{array}{l}\text { Number of } \\
\text { cases }\end{array}$ & $\begin{array}{l}V \max \\
\text { Hopf method } \\
(\mathrm{m} / \mathrm{s})\end{array}$ & $\begin{array}{l}V \min \\
\text { Hopf method } \\
(\mathrm{m} / \mathrm{s})\end{array}$ & $\begin{array}{l}\text { Range } \\
(\mathrm{m} / \mathrm{s})\end{array}$ & $\begin{array}{l}V \max \\
\text { classic method } \\
(\mathrm{m} / \mathrm{s})\end{array}$ & $\begin{array}{l}\text { Terminal } \\
\text { latency } \\
(\mathrm{m} / \mathrm{s})\end{array}$ \\
\hline Normals & $\leqslant 40$ & 11 & $52 \cdot 2 \pm 3 \cdot 3$ & $42 \cdot 2 \pm 3 \cdot 5$ & $10 \pm 4 \cdot 2$ & $52 \cdot 0 \pm 2 \cdot 5$ & $4 \cdot 6 \pm 0.6$ \\
\hline Normals & $>40$ & 10 & $48 \cdot 3 \pm 4 \cdot 7$ & $38 \cdot 8 \pm 3 \cdot 8$ & $9 \cdot 5 \pm 2 \cdot 5$ & $49 \cdot 2 \pm 5 \cdot 1$ & $4 \cdot 5 \pm 0.9$ \\
\hline Uraemics on dyalisis & $>40$ & 8 & $\begin{array}{l}38 \cdot 9 \pm 3 \cdot 7 \\
\mathrm{p}<0.001\end{array}$ & $\begin{array}{l}31 \cdot 5 \pm 1 \cdot 9 \\
p<0.001\end{array}$ & $\begin{array}{l}7 \cdot 0 \pm 2 \cdot 1 \\
\mathrm{NS}\end{array}$ & $\begin{array}{l}40 \cdot 8 \pm 2.9 \\
\mathrm{p}<0.001\end{array}$ & $\begin{array}{l}4.9 \pm 0.8 \\
\text { NS }\end{array}$ \\
\hline Uraemics on diet & $>40$ & 5 & $\begin{array}{l}42 \cdot 1 \pm 2 \cdot 6 \\
\text { NS }\end{array}$ & $\begin{array}{l}35 \cdot 4 \pm 1 \cdot 0 \\
\text { NS }\end{array}$ & $\begin{array}{l}7 \cdot 7 \pm 4 \cdot 3 \\
N S\end{array}$ & $\begin{array}{l}46 \cdot 2 \pm 2 \cdot 4 \\
\text { NS }\end{array}$ & $\begin{array}{l}4 \cdot 6 \pm 0 \cdot 4 \\
\text { NS }\end{array}$ \\
\hline Diabetics & $\leqslant 40$ & 6 & $\begin{array}{l}43 \cdot 4 \pm 5 \cdot 1 \\
p<0.001\end{array}$ & $\begin{array}{l}36.5 \pm 3.8 \\
\mathrm{p}<0.001\end{array}$ & $\begin{array}{l}7 \cdot 6 \pm 3 \cdot 3 \\
\text { NS }\end{array}$ & $\begin{array}{l}44.8 \pm 2 \cdot 7 \\
p<0.001\end{array}$ & $\begin{array}{l}4 \cdot 2 \pm 0 \cdot 7 \\
\text { NS }\end{array}$ \\
\hline Diabetics & $>40$ & 7 & $\begin{array}{l}4 i \cdot 8 \pm 7 \cdot 5 \\
p<0.01\end{array}$ & $\begin{array}{l}32.9 \pm 5 \cdot 1 \\
\mathrm{p}<0.05\end{array}$ & $\begin{array}{l}8 \cdot 9 \pm 2 \cdot 9 \\
\mathrm{NS}\end{array}$ & $\begin{array}{l}42 \cdot 3 \pm 3 \cdot 3 \\
\mathrm{p}<0.05\end{array}$ & $\begin{array}{l}4 \cdot 6 \pm 0 \cdot 5 \\
\text { NS }\end{array}$ \\
\hline $\begin{array}{l}\text { Exposed to toxic agents } \\
1^{\circ} \text { group }\end{array}$ & $\leqslant 40$ & 7 & $\begin{array}{l}43 \cdot 7 \pm 2 \cdot 8 \\
p<0 \cdot 001\end{array}$ & $\begin{array}{l}35 \cdot 7 \pm 1 \cdot 2 \\
\mathrm{p}<0 \cdot 001\end{array}$ & $\begin{array}{l}8 \cdot 0 \pm 4 \cdot 0 \\
\text { NS }\end{array}$ & $\begin{array}{l}45 \cdot 6 \pm 4 \cdot 0 \\
0<0 \cdot 01\end{array}$ & $\begin{array}{l}4.8 \pm 0.9 \\
\text { NS }\end{array}$ \\
\hline $2^{\circ}$ group & $\leqslant 40$ & 6 & $\begin{array}{l}50 \cdot 1 \pm 2 \cdot 8 \\
\text { NS }\end{array}$ & $\begin{array}{l}42 \cdot 0 \pm 3 \cdot 0 \\
\text { NS }\end{array}$ & $\begin{array}{l}8 \cdot 1 \pm 2 \cdot 0 \\
\mathrm{NS}\end{array}$ & $\begin{array}{l}51 \cdot 8 \pm 4 \cdot 3 \\
\text { NS }\end{array}$ & $\begin{array}{l}5 \cdot 0 \pm 1 \cdot 0 \\
\text { NS }\end{array}$ \\
\hline $3^{\circ}$ group & $\leqslant 40$ & 9 & $\begin{array}{l}46 \cdot 9 \pm 3 \cdot 7 \\
\text { NS }\end{array}$ & $\begin{array}{l}38 \cdot 9 \pm 3 \cdot 1 \\
\text { NS }\end{array}$ & $\begin{array}{l}8 \cdot 0 \pm 3 \cdot 3 \\
\mathrm{NS}\end{array}$ & $\begin{array}{l}49 \cdot 4 \pm 3 \cdot 7 \\
\text { NS }\end{array}$ & $\begin{array}{l}4.5 \pm 0.5 \\
\text { NS }\end{array}$ \\
\hline
\end{tabular}

Statistica' significance evaluated by Student's $t$ test. NS = not significant. 
to two subjects with very large ranges $(17.6$ and $17.8 \mathrm{~m} / \mathrm{s}$ ). Minimal MNCV was impaired in uraemic patients on dialysis, in diabetics and in those exposed to one toxic agent. Minimal MNCV was not different from normal in uraemic patients on diet and in the other two groups of those exposed to toxic agents. Maximal MNCV obtained with the classic method or by Hopf's method gave similar results. Terminal latency values always were normal.

In the group of older normal subjects there were more fibres with slow velocity (shown by a shift of the histogram to the left), compared with younger subjects. The same was evident in groups 2 and 3 of subjects exposed to toxic agents.

\section{Discussion}

The measurement of minimal MNCV and of the minimal/maximal range of conduction velocity gave limited additional diagnostic contribution compared to the maximal velocity value alone. Others, however, using the same technique, have demonstrated that the measurement of the range of velocity of motor nerve fibres may provide a more precise estimate of damage of the peripheral nerves than that of the maximum conduction velocity alone. ${ }^{1256}$ Our failure to find such changes might be due to the differences in the kind and severity of pathology investigated. Analysis of the histograms, however, might be useful. In some groups (older normals compared with the younger ones, and in the combined group 2 and 3 of the subjects exposed to toxic agents in whom maximal and miminal velocity values did not differ from normal) there was a shift towards the left of the conduction values of fibres with intermediate velocity, independent of the maximal and minimal values.

\section{References}

1 Hopf HC. Untersuchungen uber die Unterschiede in der Leitgeschwindigkeit motorischer Nervenfasern beim Menschen. Deutsch $Z$ Nervenheilk, 1962; 183:579-89.

2 Hopf HC. EMG study on so called mononeuritis. Arch Neurol 1963; 9:307-12.

3 Hausmanowa-Petrusewich I, Kopec J. An evaluation of the method of antidromic stimulation in human peripheral motor nerves. Electromyography $1968 ; 8: 105-13$.

4 Tackmann W, Ullerich D, Lehman HJ. Transmission of frequent impulse series in sensory nerves of patients with alcoholic polyneuropathy. Eur Neurol 1974; 12:317-30.

5 Perfetti CC, Ferro Milone F, Pacchiani A. Studio dei valori di dispersione della velocità di conduzione delle fibre motorie negli alcolosti. Riv di Neurol 1967; 37:453-61.

6 Hopf HC, Althaus HH, Vogel P. An evaluation of the course of peripheral neuropathies based on clinical and neurographical re-examinations. Eur Neurol 1973; 9:90-104. 